\title{
ALÍ CALDERÓN: LA RECONSTRUCCIÓN LÍRICA DE LA HISTORIA DE LA CULTURA MEXICANA
}

\author{
Alí Calderón: The lyrical reconstruction \\ of the history of Mexican culture
}

Nieves García Prados

Fecha de recepción: 24 de febrero de 2016.

Fecha de aceptación: 8 de agosto de 2016. 


\section{Resumen}

La poesía de los últimos años se ha caracterizado por una conexión entre los autores de Hispanoamérica y España, entre los que destaca una polifonía de voces. No obstante, existen actualmente dos tendencias entre los poetas de hoy: una conocida como la poética del fragmento o el neobarroco y otra de un corte más realista y que tiene como prioridad la comunicación y la búsqueda de la emoción. En este último grupo se enmarca el llamado movimiento de Poesía ante la Incertidumbre, cuyos precursores apuestan por una poesía que se entienda y que se enfrente a las incertezas actuales. El más joven del grupo es el mexicano Alí Calderón, en el que encontramos una preocupación por la historia y la necesidad de reconstruir de forma lírica la cultura y la tradición de su país.

Palabras clave: poesía, historia, Poesía ante la Incertidumbre, identidad mexicana.

\section{Abstract}

The poetry of recent years has been characterized by a connection between the authors of Latin America and Spain, among which we can find a polyphony of voices. However, there are nowadays two trends among these poets: poetics of the fragment or the neo-baroque and one more realist and whose priority is communication and the search for emotion. In this last group, we can find the poets of the movement known as Poetry Facing uncertainty, which precursors are betting on a poem to be understood and to confront the current uncertainties. The youngest of the group is the Mexican Ali Calderon, where we can find a concern for history and the necessity to rebuild lyrically the culture and tradition of his country.

Keywords: poetry, history, Poetry Facing Uncertainty, Mexican identity. 


\section{Introducción}

$\mathrm{L}$ a literatura de los últimos cinco años se ha caracterizado por un aumento extraordinario de la conexión entre las poéticas de Hispanoamérica y España, toda vez que las fronteras físicas han sido derribadas por un siglo XXI tecnológico que ha dejado atrás las dificultades de la comunicación transoceánica. Las nuevas generaciones de esta nueva era, de autores nacidos después de 1970, se han caracterizado por una polifonía de voces, lo que el crítico José Luis Morante llama la "polifonía generacional" (2016: 12). En su opinión, nos encontramos ante una "convivencia sosegada de idearios", y ante un panorama en el que los "monopolios estéticos" han sido superados. Ya, sostiene Morante en la introducción de la antología de poesía joven Re-generación, "no hay camisas de fuerza ni limitaciones programáticas y los poemas en red cuentan con una repercusión cosmopolita e instantánea" (2016: 12).

No obstante, sí pueden distinguirse en la poesía actual de España e Hispanoamérica dos grandes corrientes en la poesía escrita por autores nacidos después de 1970: una de corte más realista, que le da una preponderancia al sentido y que tiene como prioridad la comunicación y otra de corte más barroco, más hermética.

En Hispanoamérica, el camino ha sido similar que en España ${ }^{2}$, aunque diríamos que de mayor profundidad y complejidad. La confrontación se produce en tierras americanas en términos más estéticos que ideológicos, dividiéndose la poesía entre una corriente coloquialista o conversacional y la poesía neobarroca, desarrollada especialmente en los años ochenta. Ernesto Cardenal o José Emilio Pacheco son los representantes más relevantes de esa corriente conversacional, de la que es deriva natural en América el movimiento Poesía ante la incertidumbre, que no deja de ser claridad, una intensificación reflexiva condicionada por la introspección y toques de simbolismo en ocasiones (Sánchez, 2015: 43), partiendo de la emoción como límite, como fin último.

Tratemos más a fondo el asunto de Poesía ante la incertidumbre. En 2011, un grupo de ocho poetas de España e Hispanoamérica consideraron que era el momento de abordar la situación actual de la poesía y de preguntarse cómo este género se había ido acorralando a sí mismo, haciéndose casi invisible. Lo hicieron en un libro titulado Poesía ante la incertidumbre, en el que ofrecían una pequeña muestra de sus poemas. Los autores de esta primera edición del libro fueron Jorge Galán (El Salvador), Raquel Lanseros (España), Alí Calderón (México), Fernando Valverde (España), Francisco Ruiz Udiel (Nicaragua), Andrea Cote (Colombia), Daniel Rodríguez Moya (España) y Ana Wajszczuk (Argentina), todos ellos menores de 40 años y con unas amplias trayectorias.

El libro viene precedido de un texto firmado por los ocho poetas con el título Defensa de la poesía, en el que señalan que, en medio de la incertidumbre actual, la labor de la poesía debería ser no añadir más oscuridad, sino tratar de aportar algo de luz. Los autores describieron la existencia de un problema en la poesía actual, un

2- En España habría que distinguir un tipo de poesía clara, que tiene como objetivo último emocionar sin renunciar a un cierto preciosismo formal. Esta poesía es la que defienden los que reelaboran la llamada Poesía de la Experiencia, que forman parte de un movimiento más amplio a nivel internacional que se denomina Poesía ante la Incertidumbre. Establecer una comunicación entre el poeta y el lector es el centro del esfuerzo de estos autores, que pretenden ante todo emocionar. De otro lado, se encuentra la conocida como poética del fragmento, que pone el foco del poema en el mensaje y su elaboración, confiriendo una mayor oscuridad a los textos. Para el fragmento, la comunicación no es lo primordial, sino una búsqueda de la belleza que descansa en el mensaje, en lo estético (Sánchez, 2015: 53). 
problema de comunicación. Consideraron que la poesía había perdido su condición de género popular y que las tendencias mayoritarias (de una poesía que se centra en el mensaje, sin tener en cuenta al lector) habían propiciado que hubiera dejado de entenderse, la poesía había dejado de estar dentro del tradicional esquema de la comunicación (emisor-receptor).

En su discurso, en el que se apuesta por la necesidad de recuperar esa comunicación perdida entre el escritor y el lector, dan una gran importancia a la Historia (la cuarta palabra del prólogo y el primer nombre propio que nos encontramos). En su reflexión sobre nuestro tiempo actual, un tiempo "marcado por la incertidumbre", aluden a la caída de las grandes ideologías del siglo XX. Podemos decir por tanto que para comprender la incertidumbre del presente, hay que tener en cuenta los derrumbes del pasado: el capitalismo y el comunismo, hoy dos grandes incertezas.

De los Poetas de la Incertidumbre, el más joven es Alí Calderón, nacido en Ciudad de México (México) en 1982. Entre sus obras podemos destacar Imago Prima (2005), Ser en el mundo (2008), En agua rápida (2013) y Las correspondencias (2015). En este último volumen, tal y como señala Marco Antonio Campos, Calderón "combina admirable y terriblemente un cuadro de los rituales sangrientos de los mexicas y la lacerante situación de México". Es decir, Calderón se propone llevar a cabo una reconstrucción lírica de pasajes de la historia que abarcan casi la totalidad de la cultura mexicana.

El joven poeta tiene un conocimiento de la historia desde dos perspectivas: lo que podemos denominar la historia del tiempo presente ${ }^{3}$, es decir aquellos hechos históricos que ha vivido como testigo, o de los que ha tenido conocimiento a través de la tradición oral o escrita, sean o no cercanos a su biografía.

En su obra podemos encontrar continuas referencias a la historia de su país, desde el México prehispánico hasta la guerra contra el narco actual, con expresas menciones a los problemas que arrastra la sociedad y la política mexicanas. Partiendo del concepto que desarrolló Carl Jung, alumno de Freud, sobre el "inconsciente colectivo" (1995:101), o la forma en la que se conserva y transmite la herencia común de la humanidad. Calderón usa esa idea para concluir que el tiempo no existe, que todos los tiempos conviven a la vez, y la lleva a su poesía, jugando con el idioma, y mezclando desde arcaísmos o palabras del siglo XIX con referencias a la tecnología.

En este artículo vamos a llevar a cabo un análisis de la aparición de los hechos históricos en su poesía, de forma cronológica inversa, de lo más actual a lo más lejano a su biografía. Por tanto, en primer lugar vamos a analizar aquellos acontecimientos de los que ha tenido una experiencia histórica, sin olvidar que proceden de una herencia anterior.

\section{México o la construcción de un inconsciente colectivo}

Para adentrarnos en el análisis de la poesía de Calderón, tenemos que reflexionar acerca de cómo el pasado prehispánico de México ha vuelto a cerrar el círculo de la historia con el final del siglo XX, constatando la existencia de lo que Jung llama los arquetipos, entendidos como "formas típicas de conducta que, cuando llegan a ser conscientes, se manifiestan como representaciones, al igual que todo lo que llega a ser contenido de conciencia" (Jung, 1992: 278).

Por eso nos adentraremos en primer lugar en cómo ha sido en México el crecimiento del negocio de la dro-

3- De acuerdo a la definición que hace Soto Gamboa (2004: 106), por historia del tiempo presente entendemos la "posibilidad de análisis histórico de la realidad social vigente, que comporta una relación de coetaneidad entre la historia vivida y la escritura de esa misma historia". 
ga, sobre todo en el norte del país, tal y como explica el periodista británico Ioan Grillo, en su libro El narco (2012: 24). Ya desde los años sesenta y setenta el cultivo de marihuana y amapola era un negocio importante para México, especialmente en estados como el de Guerrero, Michoacán, Sinaloa, Durango o Chihuahua, estos tres últimos conocidos como el "Triángulo Dorado", por toda la droga que producen (Grillo, 2012: 48):

Sin embargo, en el comercio de la droga del mundo, los mexicanos tenían en los años setenta un papel secundario, eran simplemente intermediarios. La droga la producían los colombianos y los mexicanos la trasladaban a Estados Unidos. Con la muerte de Pablo Escobar ${ }^{4}$, se redefinieron las relaciones del narcotráfico y entonces los cárteles mexicanos tomaron la hegemonía, según Roberto Saviano, quien en la primera mitad de su libro Cero Cero Cero (2014), relata cómo se crearon los cárteles de la droga en México y cómo Joaquín Guzmán Loera, conocido como el 'Chapo’ Guzmán, se convirtió en "el que manda” (2014: 59), tras haber derrotado a todos sus competidores.

Saviano explica cómo Miguel Ángel Félix Gallardo (2014: 34-45), que había trabajado como policía federal de México, creó los cárteles como hoy se conocen, es decir, grupos bien organizados que gestionan la droga, su producción, su distribución y sus precios. A Gallardo, apodado 'El Padrino', se le considera el zar mexicano de la cocaína. Pronto, se alió con Pablo Escobar, que le pidió ayuda para distribuir los estupefacientes en Estados Unidos.

Los cárteles fueron perfeccionando el negocio y los mexicanos dejaron de ser meros transportistas para convertirse en verdaderos distribuidores. Saviano describe en Cero, cero, cero cómo en 1989 El Padrino convocó a todos los narcos más poderosos del país en un complejo turístico de Acapulco para organizar el negocio. Su objetivo era subdividir los territorios, lo que permitiría a los capos de la droga controlar sus propias plazas, es decir se "estaba privatizando el mercado de la droga en México" y se estaba "abriendo a la competencia":

Nacían en aquel momento los cárteles del narcotráfico, exactamente tal como existen hoy más de veinte años después. Nacían organizaciones criminales que ya no tenían nada que ver con el pasado. Nacían instituciones con un territorio de su competencia sobre el que imponer tarifas y condiciones de venta, medidas de protección e intermediación entre productores y consumidores finales (Saviano, 2014: 47).

Comenzó entonces la hegemonía del negocio de estupefacientes en México, que llegó a tales extremos que se apoderó de todos los espacios públicos del país, hasta el nivel de convertirse en una suerte de narcoestado 5 , del que comenzó a hablarse en la primera década del año 2000. En 2008, el historiador mexicano Enrique Krauze (2008: s/p) avisó de que México corría el riesgo de convertirse en un narcoestado si no se libraba la

4- Escobar, fundador y jefe del cártel de Medellín y conocido como 'El Patrón', murió el 2 de diciembre de 1993 tras ser abatido a tiros por quince policías de un grupo especial creado para su captura, bautizado como Bloque de Búsqueda, en el tejado de su casa en Medellín, después de que fuera localizado tras ponerse en contacto vía telefónica con su familia, tal y como relata Alonso Salazar en La parábola de Pablo (Planeta, 2001). "Tras 499 días de persecución, Pablo queda derrumbado sobre el techo con sus 115 kilos y con sus pies descalzos. Viste bluyín y camiseta azul oscura con ribetes rojos en las mangas y en su billetera cargaba una pequeña estampa del Divino Niño. La noticia se propaga por todo el país y rebota hacia el mundo entero: ha muerto el gran capo del narcotráfico, el criminal mayor (Salazar, 2012: 345).

5- El neologismo "narcoestado" (narco: droga; estado: conjunto de instituciones) se utiliza para definir a aquellos países con instituciones políticas muy influenciadas por el narcotráfico e incluso con miembros que compatibilizan sus cargos públicos con responsabilidades en las redes del tráfico de drogas. El término comenzó a utilizarse en los años 80 en alusión a Colombia, que, tras la muerte de Pablo Escobar, ha mejorado mucho su situación. Ahora, se usa habitualmente para aludir a países como Kosovo, Guinea-Bissau o México. 
guerra contra la ola de violencia provocada por el narcotráfico, durante una conferencia en la Casa de América de Madrid'.

Este narcoestado sucedió de modo paralelo a la decadencia del sistema político mexicano representado por el Partido Revolucionario Institucional (PRI), conocido hasta el año 2000 como el "partido único"”.

El partido oficial, el PRI, se caracterizaba por negociar, por tener vínculos, nexos que rallaban en el cinismo, nexos como que había un general llamado Gutiérrez Rebollo que era el encargado del combate al narcotráfico, era un empleado de uno de los capos de la mafia, Amado Carrillo, conocido como El Señor de los Cielos, porque se inventó el método de meter la droga en Estados Unidos en los aviones (Alí Calderón: 2015) ${ }^{8}$.

Otro de los hitos en la historia reciente de México se produjo en 2006, cuando se celebraron unas elecciones que dieron como ganador al candidato del PAN, Felipe Calderón, frente al candidato de la izquierda, Andrés Manuel López Obrador, del Partido de la Revolución Democrática o PRD, que consideró que se produjo un "fraude electoral".

Tras la toma de posesión de Felipe Calderón, éste adoptó una decisión inédita ante el estado de inseguridad e indefensión que vivía el país, que consistió en sacar al ejército de los cuarteles para combatir al narcotráfico, lo que se conoció como "Guerra contra el narco", que incluyó tolerancia cero con la delincuencia organizada.

La reacción del Gobierno de Calderón en 2007 fue lanzar una ofensiva casi desesperada por recuperar territorios en manos del narco, lo cual contribuyó fatalmente a escalar las confrontaciones de los grupos criminales, entre ellos y contra las fuerzas federales o las policías locales, a veces coludidas con los delincuentes. Desde entonces, la incesante ola de violencia se expandió del comercio de drogas a todos los giros criminales: secuestros, extorsiones, asaltos, asesinatos, robo de combustible en oleoductos, tráfico de personas, delitos de toda índole. Entre 2008 y 2011 la tasa de homicidios subió de 9 a 24 por cada 100.000 habitantes. Ha sido un huracán de violencia y, aunque los índices han disminuido un poco, continúa (Krauze: 2015: s/p) .

Sin embargo, de esta guerra frontal contra el narco se obtienen saldos negativos como la violación de derechos humanos, o un saldo de 150.000 muertos, que ha convertido a México en uno de los países más violentos de la tierra que no está en una guerra ${ }^{10}$.

6- El artículo puede consultarse en el archivo de El Universal, en http://archivo.eluniversal.com.mx/notas/547793.html

7- De hecho, desde 1929 todos los presidentes de México fueron integrantes del PRI o partidos antecesores hasta que en el año 2000 Vicente Fox, candidato del Partido de Acción Nacional (PAN), resultó ganador en las elecciones federales.

8- Extracto de la entrevista realizada por la autora a Alí Calderón el 13 de octubre de 2015.

9- Opinión de Enrique Krauze en el artículo Crimen sin castigo, publicado en la sección de Opinión de el diario El País el 9 de noviembre de 2015. Puede consultarse en el enlace http://elpais.com/elpais/2015/11/06/opinion/1446830205_420907. html

10- Según un informe de la organización Seguridad, Justicia y Paz de México, entre las 50 ciudades más violentas del mundo figuran ocho mexicanas. En el tercer puesto del ranking global, después de la ciudad hondureña San Pedro Sula y de Caracas 
Sumado a esto, en la otra arista del problema se encuentra la incapacidad del estado para asegurar el bienestar de sus habitantes. La pauperización del país comenzó a crecer en los años 80, cuando se alcanzó una inflación del 100 por $100^{11}$, y ha llevado a muchos mexicanos desde entonces a migrar a Estados Unidos.

Se estima que un millón de mexicanos documentados y no documentados emigran hacia los Estados Unidos cada año ${ }^{12}$, a los que hay que sumar unos 400.000 mexicanos que son repatriados anualmente de la Unión Americana (de 2008 a 2014), según datos de la Unidad de Política Migratoria (UPM). El país de mayor recepción de emigrantes mexicanos sigue siendo Estados Unidos, que según el Instituto para los Mexicanos en el Exterior (IME), acoge hoy, alrededor de 11,5 millones de personas nacidas en México, lo que convierte la frontera entre estos dos países en el principal corredor migratorio del mundo, después del de Rusia-Ucrania. Entre las razones que llevan a los mexicanos a emigrar se encuentran el desempleo, la inseguridad y la pobreza extrema ${ }^{13}$. Ahora, en México, hay unos 55 millones de habitantes en la pobreza ${ }^{14}$.

Otro ejemplo de cómo el estado mexicano se distinguió por su incapacidad para operar es el terremoto del año 1985 en el que murieron cien mil personas en la Ciudad de México. Sin embargo, y ante la falta de respuesta del Gobierno, en México nació entonces lo que se llama la sociedad civil, es decir que la gente, a través del trabajo solidario, sacó adelante esa tragedia ${ }^{15}$.

Todo lo que ha acontecido en México en los últimos 30 años no podía estar ausente en la obra del poeta Alí Calderón y en la última parte de su libro Las correspondencias (2015), en la sección titulada Piedra de sacrificio podemos encontrar el poema Democracia mexicana, un título irónico si tenemos en cuenta la trayectoria del país en su pasado reciente.

Con Democracia mexicana, Calderón construye, a modo de mosaico, la historia de México y combina dos experiencias sobre la misma realidad. En la primera parte, el autor escribe sobre una realidad cotidiana en el país, el hallazgo de un cadáver en una bolsa de plástico, y en la segunda, combina pasado y presente haciendo uso del lenguaje de los conquistadores en el México prehispánico, del que hablaremos más adelante en esta investigación.

(Venezuela), se encuentra Acapulco, con 113 homicidios por cada mil habitantes. Ciudad Juárez, que había tenido el primer lugar mundial en los años 2008, 2009 y 2010, en 2011 tuvo el segundo lugar, en 2012 el 19, ocupa la posición 37 en el 2015 , según este informe, que puede consultarse en el enlace. http://www.seguridadjusticiaypaz.org.mx/biblioteca/download/6prensa/177-por-tercer-ano-consecutivo-san-pedro-sula-es-la-ciudad-mas-violenta-del-mundo

11- El índice de inflación en México, durante 1982, alcanzó el ciento por ciento, según un análisis del Centro de Estudios Económicos del Sector Privado (CEESP). De la noticia se hizo entonces eco el diario El País. Puede consultarse la noticia en el enlace siguiente: http://elpais.com/diario/1983/01/07/economia/410742007_850215.html

12- Según consta en un documento de fecha 18 de diciembre de 2015 publicado por la ONG Comisión Nacional de los Derechos Humanos (CNDH), que considera que el tema migratorio en México es de "urgente abordaje". El informe puede consultarse en su web http://www.cndh.org.mx/.

13- De esto ya alertó el subcomandante Marcos en uno de sus primeros comunicados después de que los zapatistas tomaran San Cristóbal de las Casas, y otras cabeceras municipales de Chiapas el 1 de enero de 1994: "Las graves condiciones de pobreza de nuestros compatriotas tienen una causa común: la falta de libertad y democracia. Nosotros consideramos que el respeto auténtico a las libertades y a la voluntad democrática del pueblo son los requisitos indispensables para el mejoramiento de las condiciones económicas y sociales de los desposeídos de nuestro país” (Poniatowska y García de León, 1994: 73).

14- Según un informe del Consejo Nacional de la Política de Desarrollo Social (Coneval) de México, presentado el 23 de julio de 2015, en México había en 2014 un total de 55.3 millones de personas en la pobreza, más de dos millones más que dos años antes, en 2012. El informe completo puede consultarse en la web de Coneval, en http://www.coneval.gob.mx/ Paginas/principal.aspx

15- El propio tenor Plácido Domingo perdió a cuatro familiares tras el seísmo, del que informó ampliamente la prensa española. Por ejemplo, el 23 de septiembre de 1985 el diario El País puso en duda la respuesta del gobierno mexicano y tituló de la siguiente forma una de las informaciones en su sección de internacional: "La movilización popular pone en tela de juicio la eficacia del Gobierno", que puede consultarse en el siguiente enlace http://elpais.com/diario/1985/09/23/internacional/496274413_850215.html 
La primera parte de este poema parte de una imagen que Calderón encontró en el denominado Blog del narco, una web muy conocida en México con la que se hace propaganda del narcotráfico y que utilizan los propios cárteles de la droga para enviarse mensajes ${ }^{16}$. Se trataba de una suerte de muladar, de un basurero de restos humanos, una visión que Calderón mezcla con otra experiencia propia, la de la noticia del hallazgo del cadáver de una recién nacida en una bolsa de basura.

Fue el 27 de abril de 2013, y del acontecimiento se hicieron eco varios medios en México, en los que este tipo de sucesos son ya casi cotidianos. El informador relata en su edición digital cómo la bebé fue encontrada en el basurero en Tonalá, en el estado de Jalisco:

De acuerdo a las autoridades, se recibió un reporte a las 13:36 horas de que uno de los pepenadores ${ }^{17}$ que trabajaba en un pequeño tiradero ubicado en las cercanías de la entrada del vertedero Los Laureles (que recoge los desechos de Guadalajara y Tonalá) vio cuando una góndola de basura descargaba los residuos, entre los cuales había una bolsa plástica negra de donde alcanzó a ver que salía una extremidad del bebé, que se hallaba envuelto en una toalla verde ${ }^{18}$.

Después de oír en las noticias aquel suceso, el poeta Alí Calderón decidió escribir sobre aquella historia en Las correspondencias (2015: 67).

otro cadáver encontrado en una bolsa negra

cerca de ahí un cuerpo el viento un puente

a dos cuadras:

una cabeza hirsuta ojos abiertos

Calderón deja entrever en estos versos un país que tiene a la muerte, a los crímenes del narco y a la guerra entre cárteles de la droga como elementos cotidianos de la rutina ${ }^{19}$. La historia le permite al poeta establecer un símil sobre qué es el estado de derecho en México y qué es la democracia mexicana. La de México es una democracia nueva, pero muerta, putrefacta y malograda, como la niña aparecida en la bolsa, ese cadáver con la carne putrefacta ("el hedor el moho en la carne"), como símbolo del sistema político mexicano. De hecho, México ha tenido tres elecciones limpias en los últimos 200 años: "La primera, en 1833, con Antonio López de Santa Anna, que perdió la mitad del territorio mexicano con

16- La prensa no se suele hacer eco de lo que publica El blog del narco, pero algunos medios sí han publicado información sobre su existencia. La NBC, por ejemplo, publicó el 14 de agosto de 2010 una noticia sobre las barricadas que se construían en las carreteras de Monterrey en la que califica este sitio como una web donde se publica información sobre la guerra contra el narcotráfico (http://www.nbcnews.com/id/38707292/39779522\#.VoGs7PnhC1s).

17- En México así son conocidas las personas que viven de recoger desechos que todavía se pueden aprovechar para ser vendidos. Etimológicamente, según la RAE, pepenar procede del término náhuatl pepena, es decir "escoger", "recoger".

18- La noticia puede encontrarse en la edición digital de El Informador, en la web http://www.informador.com.mx/jalisco/2013/453887/6/hallan-bebe-muerto-en-un-basurero.htm

19-Los titulares sobre la aparición de cadáveres colgados de los puentes de las ciudades son un rasgo común de la prensa no sólo mexicana, sino también de la internacional. El 15 de octubre de 2015 varios medios en español publicaron la noticia del hallazgo del cadáver de un joven de 25 años que estaba colgado de un puente de Ciudad de México con signos de tortura (http://cnnespanol.cnn.com/2015/10/19/autoridades-encuentran-a-hombre-colgado-de-puente-en-la-ciudad-demexico/\#0). El objetivo, amedrentar al cártel rival, en este caso como represalia contra del cártel del Golfo, al que se le acusó de "calentar la plaza" por atraer la atención de las fuerzas de seguridad con atentados. 
Estados Unidos. La segunda fue con Benito Juárez en 1871 y la tercera con el presidente Vicente Fox, en el año 2000" (Calderón: 2015).

A este símil que utiliza Calderón se une ese lenguaje vacío, acrítico, y desprovisto de la carga del significado de lo que enuncia propio de la política o de los medios de comunicación. El autor usa una prosa cansina, en el nivel de la prosa periodística, alejada emocionalmente de lo que se describe. La elección de esta prosa, casi hueca de significado, quiere emular a las noticias que diariamente se difunden en los medios de comunicación. El mismo tono se emplea para informar del índice de la bajada de la pobreza, de la aprobación de un punto de la reforma migratoria que del hallazgo de 30 ejecutados con cabezas cercenadas.

entre otras noticias: treinta ejecutados el fin de semana tiro de gracia algunos con marcas de tortura el rescate fallido de un secuestro un dedo un anillo un dato de periódico

entre otras noticias: terminaron e iniciaron las campañas hay buena voluntad en Washington la reforma migratoria este bimestre se abate en un punto la pobreza el bienestar la dicha (Calderón, Las correspondencias, 2015: 67)

Así, Calderón usa el lenguaje poético para llamar la atención sobre ciertos hechos, en este caso el hallazgo del cadáver de una niña recién nacida en una bolsa de basura, para reformularlos, para reformular la realidad de una forma que no se encuentra en el lenguaje referencial. Sin embargo, sí que genera lo que Michael Riffaterre denomina una ilusión referencial, con la que consigue un efecto de verdad y potencia la veracidad para que el lector sienta que el texto es real, es crudo y que sucedió. El poeta mexicano hace una interpretación personal de lo ocurrido, que, siguiendo a Riffaterre (2000: 166) es "una manera indirecta de recordarnos que la obra de arte es resultado de una intención, de un pensamiento, de una voluntad creadora".

Para Calderón, la historia puede ser un fundamento de la poesía, y en este caso sirve para convertirse en una escenografía del sujeto (Calderón: 2015). El espacio de la poesía es el espacio que tiene el sujeto, el actor social, el hombre, para afirmarse, para tomar la palabra y para reflexionar sobre sí mismo, pero dentro del contexto social e histórico en el que se sitúa.

La imagen de la niña en el basurero, en realidad, se trata de un pretexto para construir una suerte de alegoría que potencia la idea de que todo, el sistema político, la moral, la ética, los afectos, los instintos básicos, todo en México, está podrido, de que los arquetipos de Jung, los patrones típicos de conducta, se repiten.

Totalmente distinta, aunque con el mismo trasfondo, es la segunda parte de este poema titulado Democracia mexicana, en la que el autor consigue una textura lingüística extraña, recuperando la forma en la que hablaban los conquistadores, que puede considerarse que destruyeron de la misma forma que fundaron, y consigue así una doble misión simbólica.

E subimos las ciento y catorce gradas longas de aquel cú ${ }^{20}$

Sus piedras ennegrecidas nos quemaron las manos de tan ásperas

(Calderón, Las correspondencias, 2015: 68)

20- En las crónicas de las conquistas de la Nueva España la palabra cú aparece en referencia al templo. En la RAE se recoge su definición: En los cronistas de Indias, templo o adoratorio de los indígenas prehispánicos en Mesoamérica. 
El tono de esta segunda parte recuerda a las Cartas de Relación $n^{21}$ de Hernán Cortés o a las crónicas de Bernal Díaz del Castillo en La historia verdadera de la Nueva España ${ }^{22}$, con palabras tomadas de sus obras e imitando ese lenguaje. Por eso, podemos considerar que Calderón hace aquí uso de lo que en la poesía norteamericana denomina "apropiación ${ }^{23}$ ", es decir, usar palabras de otros, desfamiliarizarlas o descontextualizarlas, y acomodarlas en una suerte de collage que cree una nueva realidad, un nuevo contexto. Escribe Calderón:

Vide allí los pueblos comarcanos

el tianguiz de ocote y tigres

Tlatelulco

Fue desde la placeta que arriba muy se face que oteamos

el agua dulce que se viene de Chapultepec

Iztapalapa Tlacopan Tepeaquilla todo señoreado por nos ojos

(Calderón, Las correspondencias, 2015: 68)

Está describiendo la llegada de los españoles a Tenochtitlan, donde hoy se levanta Ciudad de México, como así lo contara también Bernal Díaz del Castillo:

solamente diré que alrededor de aquel gran patio había muchas casas y no altas, que era donde posaban e residían los papas e otros indios que tenían cargo de los ídolos. Y también tenían otra muy mayor alberca o estanque de agua, y muy limpia, a una parte del gran cu. Era dedicada solamente para el servicio del Huichilobos e Tezcatepuca, y entraba el agua en aquella alberca por caños encubiertos que venían de Chapultepeque (Díaz del Castillo, 2011: 340) ${ }^{24}$.

Calderón alude en los primeros versos de esta segunda parte al gran cu, al Templo Mayor de Tenochtitlan, que era el edificio más alto de la ciudad más poblada de América. Fue inaugurado en 1487, y tenía 114 gradas, escalinatas, desde donde se veía todo el valle de México. Las crónicas cuentan que cuando inauguraron el Templo Mayor lo celebraron con 80.000 sacrificios humanos (Calderón: 2015). Así escribe sobre el descubrimiento del Templo Mayor Calderón:

21- La primera carta escrita por Cortés a la reina doña Juana y a su hijo, el emperador Carlos V, data de 1519 y fue publicada en 1522 por el impresor Jacobo Cronberger Alemán, quien le dio el nombre de Cartas de Relación. Las cartas de Cortés al rey, que eran en realidad una "probanza" o prueba de mérito tuvieron tanto éxito cuando se publicaron que el rey se vio obligado a prohibirlas.

22- La Historia verdadera, un amplio informe de las conquistas españolas en México y Centroamérica, se publicó en 1632 en un libro de seiscientas páginas que es una consulta obligada de los historiadores de la conquista del Nuevo Mundo y de los interesados en el asunto.

23- Poetas y críticos como Marjorie Perloff se han referido al fenómeno de la apropiación, por ejemplo en su libro Unoriginal genius: Poetry by Other Means in the New Century (2010). En una entrevista realizada con motivo del congreso "The Poetry of the Americas", en Texas A\&M University, Perloff señaló: "Hoy la escritura es espesamente citativa e intertextual" (Perloff: 2007). Kenneth Goldsmith, quien escribió Uncreative Writing (2011) en el que reivindica el collage en la literatura, el "corta y pega" en la era digital, en la que se pueden copiar obras enteras a golpe de teclado, para crear algo que vaya más allá del texto, para que haga pensar (Goldsmith,2011: 14-33).

24- En la edición de la Real Academia Española, publicada por Espasa en 2011. 
Tornamos las espaldas e vimos

a constelación

bultos y cuerpos de sus ídolos

malas figuras

todos de muy mayor estatura que un gran hombre

$y$ contrahechos

de arcilla y masa y de legumbres

(Calderón, Las correspondencias, 2015: 68)

Unos versos que, inevitablemente, nos llevan también a las descripciones del atento observador militar que era Hernán Cortés en sus cartas de relación al emperador Carlos V, concretamente en su segunda relación:

Los bultos y cuerpos de los ídolos en quien estas gentes creen son de muy mayores estaturas que el cuerpo de un gran hombre. Son hechos de masa de todas las semillas y legumbres que ellos comen, molidas y mezcladas unas con otras, y amásanlas con sangre de corazones de cuerpos humanos, los cuales abren por los pechos, vivos, y les sacan el corazón y de aquella sangre que sale dél amasan aquella harina, y así hacen tanta cantidad cuanta basta para facer aquellas estatuas grandes. E también después de hechas, les ofrecían más corazones que asimismo les sacrificaban, y les untaban las caras con la sangre (Cortés, en la edición de Gayangos y Arce, 2008: 107)25.

También Bernal Díaz del Castillo describe la llegada de los españoles a este templo de la siguiente forma: "Como subimos a lo alto del gran cu, en una placeta que arriba se hacía, adonde tenían un espacio como andamios, y en ellos puestas unas grandes piedras, adonde ponían los tristes indios para sacrificar, allí había un gran bulto de cómo dragón ${ }^{26}$, y otras malas figuras, y mucha sangre derramada de aquel día" (Díaz del Castillo, 2011: 333).

Las grandes piedras a las que alude este cronista del descubrimiento del llamado Nuevo Mundo son las llamadas "piedras de sacrificio", que precisamente dan nombre a la sección del libro de Calderón en la que se encuentra el poema Democracia mexicana. La piedra de sacrificio es una piedra de tezontle ${ }^{27}$, una piedra roja que dejaban al sol y que era labrada, tallada, el lugar donde ponían al sacrificado ${ }^{28}$.

El cuchillo utilizado para matar a las víctimas se llamaba íxcuaq, y estaba hecho de sílex o pedernal.

25- Se trata de la versión del erudito historiador y bibliógrafo español Pascual de Gayangos y Arce (Sevilla, 1809-Londres, 1897), que recopiló y mandó imprimir en París en 1866 las Cartas y relaciones de Hernán Cortés al emperador Carlos V, que el conquistador escribió entre 1519 y 1544 y remitió al emperador Carlos V.

26- Díaz del Castillo se refiere aquí al Dios de la Guerra, Huitzilopochtli, al que los aztecas le ofrecían los sacrificados.

27- Hablamos de una roca roja de origen volcánico (ígnea) que se encuentra en las laderas de los cerros, volcanes o depresiones.

28- Un amplio estudio sobre el sacrificio humano en el México prehispánico como fenómeno religioso ha sido realizado por Yolotl González, quien en El sacrificio humano entre los mexicas (1985). Sobre las piedras de sacrificio, o téchcatl, explica que eran macizos, con figuras labradas, de gran altura para facilitar la operación sangrienta que suponía la extracción del corazón. 
Fray Toribio de Benavente, o Motolinía ${ }^{29}$, como se hizo nombrar por los mexicas, describe en su crónica cómo era ese cuchillo, que estaba "hecho con un hierro de lanza, no agudo mucho porque como es piedra recia y salta, no se puede parar aguda" (Motolinía, 1971: 62).

Las víctimas a sacrificar eran elegidas cuidadosamente y tenían que reunir una serie de requisitos, entre los que estaban la edad, la apariencia o la extracción social (González, 1985: 255), dependiendo de la deidad a la que se le dedicaba la ofrenda. Los niños se sacrificaban en los primeros meses del año, y los hombres eran mucho más frecuentes que las mujeres. Tenían que ser hombres que no fueran ancianos, y normalmente perfectos, aunque algunos ritos requerían deformes o enfermos.

Para conseguir víctimas, los aztecas idearon las llamadas "guerras floridas" ${ }^{30}$ cuya finalidad era, por una parte, someter a los pueblos rivales para obtener tierras, y, por otra obtener víctimas para el sacrificio. Se trataba de una especie de luchas periódicas contra los señoríos rivales de la llamada Triple Alianza (Tenochtitlan, Texcoco y Tlacopan), es decir contra Tlaxcala y Huexotzingo (León Portilla, 1961: 94).

El sacrificio masivo de personas se convertía en un espectáculo del que además participaba el pueblo. Las ceremonias más importantes se llevaban a cabo en el Templo Mayor de Tenochtitlan, en la parte superior de la pirámide, para que pudiera ser contemplado por todos lo que allí acontecía. La religión, también entre los aztecas, iba a convertirse en un instrumento de dominación ideológica.

La "muerte ritual de un ser humano", o tlacamictiliztli, tenía como objetivo conservar la armonía en el Universo. El sacrificio por extracción del corazón era el habitual, aunque también podían llevarse a cabo una serie de "torturas previas" (González, 1985: 119), como el "flechamiento" o el "despeñamiento". En el primer caso, la víctima era inmovilizada y amarrada a postes o estacas con las piernas y los brazos abiertos y después era acribillada a flechazos, y en el segundo el individuo a sacrificar era arrojado desde una altura considerable de un edificio. El tlacamictiliztli por extracción del corazón se producía de la siguiente forma:

Se colocaba a la víctima de espaldas sobre la piedra de los sacrificios o téchcatl, de tal manera que le quedara el pecho tenso; cuatro sacerdotes le sostenían los pies y las manos, y un quinto le colocaba una argolla de madera en la garganta para que no gritara. El sexto sacerdote, que era el principal, empuñaba un cuchillo de pedernal con ambas manos, y de un solo tajo le abría el pecho por debajo de las costillas o en el segundo espacio intercostal, y por la herida, con una mano, le arrancaba el corazón (González, 1985: 123-124).

El procedimiento de extracción del corazón aparece inevitablemente en el poema de Calderón Democracia mexicana:

29- Motolinía (Benavente, 1482- México, 1569) fue uno de los doce frailes franciscanos que pisaron tierra mexicana en 1524. El nombre con el que se hizo llamar procede del náhuatl y significa "el que es pobre o se aflige". Está considerado como la fuente más antigua que describe algunos de los ritos efectuados por los mexicas tanto en Tenochtitlan como en Tlaxcala o Cholula (González, 1985: 79).

30- Fue una idea original de Tlacaélel, un guerrero y consejero de varios reyes mexicas que concibió la llamada Triple Alianza de Tenochtitlan, Texcoco y Tlacopan contra los tepanecas, que agobiaban de impuestos a los aztecas. Además, tomó medidas que transformaron la vida de su pueblo, en el que creó una nueva visión místico-guerrera del mundo y el hombre (León Portilla, 1962: 46-49). 
- Revista de Ciencias Sociales y Humanidades. ISSN-P: 0188-9834 ISSN-E:2395-8669.

\author{
Tomábanlos cinco \\ dos por las piernas dos por los brazos \\ uno más por la cabeza y otro postema y landre rajábales \\ con ambas manos pedernal a modo de lanzón los pechos \\ y por aquella abertura metíale la mano \\ y le sacaba el corazón \\ (Calderón, Las correspondencias, 2015: 69)
}

El sacrificio era una ofrenda al Dios de la Guerra, Huitzilopochtlii" ${ }^{31}$ para darle energía al Sol y vencer así a las tinieblas, a la noche. Podemos decir que los aztecas consideraban que su combustible era la sangre humana, los corazones humanos. En realidad a quien sacrificaban era una especie de Dios Simbólico (León, Portilla, 1961: 94).

Esa concepción místico-guerrera llevó a los aztecas a pensar que de ellos dependía que el Universo existiera, que existiera el Sol, frente a los poderes tenebrosos de la noche. Se consideraban del lado del Bien, pero además justificaban así sus conquistas, es decir, que sometiendo otros pueblos se estaba realizando una "suprema misión" (León Portilla, 1961: 95).

La historia de los aztecas le da la oportunidad a Calderón de establecer una alegoría, una metáfora extensa, un símil, un paralelo, con la historia mexicana reciente, que de finales de $2006^{32}$ a la fecha ha vivido un baño de sangre. El poeta quiere establecer una correspondencia ${ }^{33}$, la de que cómo se vive ahora en México, con ese derramamiento de sangre, se parece mucho a aquella brutalidad, a aquel baño de sangre ritual entre los aztecas. Tiene aquí presente el joven poeta mexicano la famosa frase de Karl Marx de que la historia se repite la primera vez como tragedia y la segunda como farsa ${ }^{34}$.

Calderón, convertido en un narrador al modo de Bernal Díaz del Castillo, cuenta la escena de los soldados que suben al Templo Mayor en Tenochtitlán y están mirando toda la ciudad. Entran en el Templo Mayor, en el recinto del altar, en el apartado del dios de la guerra, que es un dios la figura informe y ojos monstruosos que les causa miedo. Es un lugar oscuro y lleno de costras de sangre que huele espantoso. Aquello que en realidad sucedió en 1519 y que cuentan tanto Hernán Cortés como Díaz del Castillo le sirve al poeta para mezclar el pasado indígena y el presente de su país. En el poema escribe:

31- Era el dios del Estado. Según explica Yolotl González, en su honor se realizaban prácticamente todos los sacrificios masivos, como parte del pacto establecido entre el pueblo mexica y "el dios que los había llevado a la cúspide del poder". "Huitzilipochtli,como dios del Estado y dios de la guerra, tenía a su cargo obtener las víctimas para que el sol continuara su tarea" (González, 1985: 143).

32- Es la fecha en la que el Gobierno mexicano decide hacer uso de las fuerzas armadas para combatir el narcotráfico. Concretamente, fue el 11 de diciembre de 2006 cuando el gobierno anunció una ofensiva contra el crimen organizado en el estado de Michoacán, que llevaba sólo ese año medio millar de asesinatos de integrantes de los distintos cárteles de la droga que operaban en la zona.

33- Una correspondencia al modo en que ya lo hiciera Baudelaire en Las flores del mal en el poema Correspondencias ("El hombre pasa a través de bosques de símbolos/que lo observan con miradas familiares").

34- La cita completa la podemos encontrar en su libro El 18 Brumario de Luis Bonaparte, en el que Marx dice textualmente: "Hegel dice en alguna parte que todos los grandes hechos y personajes de la historia universal aparecen, como si dijéramos, dos veces. Pero se olvidó de agregar: una vez como tragedia y otra vez, como farsa". 
En una torrecilla y apartamiento a manera de sala

dos altares

dos bultos

dos altos cuerpos harto astrosos

uno dellos

\section{Uichilobos}

Tenía la su cara y rostro muy ancho y los ojos disformes espantables

untado el cuerpo de engrudo y raíces y aljófares

sangre y otras varias excrecencias

$y$ colgantes ceñidas al plexo unas caras de indio

arrancadas a sus cráneos

tantas para abangar un roble

$y$ acezando por los humos del sahumerio

hube visto

todas las paredes de aquel adoratorio

tan bañado y negro de costras

y plasma asimismo en el suelo

que un rastro no exardece tal hedor e catadura

(Calderón, Las correspondencias, 2015: 68-69)

En esta segunda parte de Democracia mexicana podemos encontrar referencias a cómo el cuerpo del sacrificado durante la etapa azteca era mutilado, era partido, y en una especie de comunión ritual, se le daba a la gente para que se comiera ese cuerpo cercenado.

y el cuerpo desasido en oscura laceria descoyuntado era comido de todos y los basófilos tomados granate y bermellón los rostros

purpurecidos cientos de azumbres de aloque caudal hasta la plaza

(Calderón, Las correspondencias, 2015: 69)

Siguiendo la línea de pensamiento de Jung, el poeta establece un paralelismo con lo que está sucediendo en el México actual, con miles de muertes a costa del narcotráfico y la mutilación de cuerpos de los miembros de cárteles enfrentados para mandar un mensaje basado en la amenaza, en el terror. El poeta comienza en esta parte del texto a comenzar a mezclar pasado prehispánico y la situación actual y empieza a usar referencias modernas, como los basófilos:

y los basófilos tomados granate y bermellón los rostros

Además, en la siguiente estrofa podemos encontrar la palabra eritroci, es decir, eritrocitos, pero que el autor cercena, mutila, como los cuerpos eran y son mutilados en México: 


\author{
y echaban los restos a rodar \\ $y$ otros eritroci

$$
\text { vestían sus pellejos }
$$ \\ los muñones los tajos carne viva linfocitos \\ (Calderón, Las correspondencias, 2015: 69)
}

El poema ya comienza entonces a demostrar claramente que ha mezclado pasado y presente, prueba la "uniformidad en el tiempo y el espacio" a la que alude Jung (1992: 278), cuando Calderón escribe sobre los cadáveres que son colgados de los puentes, una práctica muy habitual entre los cárteles para hacer visibles sus amenazas cumplidas, y sobre las bolsas negras en las que, a diario, aparecen los cuerpos sin vida de los asesinados, o algún brazo, cabeza o pierna desmembrada. El poeta habla de "sátrapas" que derraman la sangre fuera de los cúes o templos, esto es, los sacerdotes que ofrecían al sacrificado, pero también los oficiantes del terror, los narcos o el propio estado:

Derramaban también sangre los sátrapas fuera de los cúes

frente al Uichilobos y en degüello

(Calderón, Las correspondencias, 2015: 70)

Es en este momento del poema cuando el mal se amplifica y significa. Y continúa

con más referencias modernas, como la cinta aislante, los puentes, y las bolsas negras:

tiernas cabezas de hombres hirsuta pelambrera

desmembrados los coágulos muslos

y antebrazos tibias allí asoma el hueso entre la grasa

y la carne después aislante cinta

les rodea narices esnifadas bocas y de unos puentes entonces

lo ponen a colgar

y el viento de las madrugadas desbravó sus fauces

envueltas en bolsas negras

allí vienen los retenes.

(Calderón, Las correspondencias, 2015: 70)

Y la conclusión es la siguiente: los cuerpos se están pudriendo, los restos se están pudriendo antes y ahora en los belfos de las ratas, en el hocico de la rata, como una suerte de símbolo de la corrupción, de la putrefacción de todo en México, de todas las estructuras, lo que podríamos denominar, tomando la idea de Jung, el arquetipo de la mexicanidad.

y allí abdómenes mamas huesos frontales

ojos

axilas anos páncreas rafagueados

pudriéndose en los belfos

de las ratas 
Señoras de esta tierra

(Calderón, Las correspondencias, 2015: 70)

El poema tiene como clara referencia el cuento de Cortázar La noche boca arriba ${ }^{35}$, en la que el escritor hace un juego entre un indígena y un hombre del siglo XX. Se trata de la historia de un joven que sufre un accidente de motocicleta y que es atendido en un hospital. Allí comienza a tener pesadillas, sueña que es un miembro del pueblo moteca que en una noche oscura tiene que huir de los aztecas, que están buscando prisioneros para llevar a cabo sus sacrificios. Vuelve a la sala del hospital, pero el sueño regresa, y esta vez ya ha sido capturado y ve cómo el sacerdote está dispuesto ya a sacrificarlo. Finalmente, el lector descubre que el sueño no era la escena del protagonista en la piedra de sacrificio, sino la del hospital ${ }^{36}$.

Con Democracia mexicana, la intención de Calderón es dar la impresión de que continúa ese derramamiento de sangre, de que el país vive en continuo sacrificio, está sacrificado. La sangre significa la herencia, la estirpe, y, como en los versos de Calderón, en México hay una constante de sacrificio. La idea principal es que México vive en un sacrificio constante, que México ha vivido en la carne abierta, en la llaga viva toda su historia. Es decir, que el país está, desde el pasado azteca, en constante caída, que está siempre en la piedra de sacrificio.

Esa es la correspondencia que quiere conseguir Calderón en este poema, en el que tiene muy presente a Carl Jung y sus estudios sobre los alquimistas medievales y sus fuentes. Para Calderón, las cosas que pasan en el espacio de lo macro, pasan en lo micro, es decir, que todo está conectado por semejanzas, siguiendo el precepto de Hermes Trismegisto de "como es arriba, es abajo", que aparece en la Tabula Smaragdina, la Tabla de Esmeralda (Arola, 2008: 51). La idea de que todo está conectado también la desarrolló el teólogo y místico bizantino Pseudo Dionisio, que pensaba que el mundo estaba hecho a la imagen y semejanza de Dios, de la ciencia de Dios (Balderas, 2008: 191):

Si esto es así todas las cosas del mundo participan de la sustancia de Dios, de la ciencia de Dios. Si esto es así, todas las cosas están relacionadas íntimamente entre sí puesto que están hechas de la misma materia. Si todo está relacionado, hay vínculos, hay ligas, entre las cosas que no conocemos, que permanecen ocultas. La idea de la poesía sería descubrir los vínculos entre las cosas, el "bosque de símbolos" del que hablaba Baudelaire (Alí Calderón: 2015) ${ }^{37}$.

En Democracia mexicana, el poeta se refiere a lo micro y a lo macro, a la historia general y a las circunstancias del sujeto. Para él, y como ya dijera Octavio Paz, el objetivo último de la poesía tiene que ser la "revelación ${ }^{38 ”}(1972: 46-47)$ :

35- Apareció en Final del juego, publicado en 1956, en su primera edición en México, en la editorial Los Presentes, y posteriormente, en 1964, segunda edición aumentada.

36- "Durante un segundo creyó que lo lograría, porque estaba otra vez inmóvil en la cama, a salvo del balanceo cabeza abajo. Pero olía a muerte y cuando abrió los ojos vio la figura ensangrentada del sacrificador que venía hacia él con el cuchillo de piedra en la mano. Alcanzó a cerrar otra vez los párpados, aunque ahora sabía que no iba a despertarse, que estaba despierto, que el sueño maravilloso había sido el otro, absurdo como todos los sueños; un sueño en el que había andado por extrañas avenidas de una ciudad asombrosa, con luces verdes y rojas que ardían sin llama ni humo, con un enorme insecto de metal que zumbaba bajo sus piernas" (Cortázar, 2003: 512).

37- Así lo señala Calderón en la entrevista realizada por la autora de este artículo el 13 de octubre de 2015.

38- En el capítulo "El lenguaje" de El arco y la lira. El poema. La revelación poética. Poesía e Historia, Paz dice "El poe- 
Puede ser la revelación de belleza, pero hay muchos tipos de poesía, puede ser revelación de una idea, aportar nueva información sobre la realidad, hay muchos tipos de poesía. Pero yo pienso que una palabra que puede agrupar todas estas búsquedas es la revelación, descubrir el lado oculto de las cosas, descubrir algo más en lo que parece simple. Baudelaire quería hacer visibles esas cosas, revelar (Calderón: 2015) ${ }^{39}$.

Calderón busca continuamente en la realidad esos símbolos, sin sucumbir a lo que Jung llama "el influjo fascinador de los arquetipos" (Jung, 1992: 68). El poeta los relaciona con la historia de su país, desde su pasado indígena hasta la actualidad, en un intento de hallar respuesta a la pregunta qué es ser mexicano, en un intento de descubrir y reflexionar sobre la identidad.

No obstante, y ante la terrible situación de México, quiere reivindicar la poesía, apostando por ella como el nuevo ethos de nuestro tiempo. No se trata de una idea nueva, ya los aztecas reflexionaron sobre qué era lo importante de la vida, como constatamos en la conversación poética que tuvieron alrededor de 1490 los sabios del mundo náhuatl, el llamado Diálogo de la flor y el canto, que Miguel León Portilla recoge en su libro Los Antiguos Mexicanos ${ }^{40}$.

De esa idea podríamos deducir también que a la sangre, a una violencia ejercida desde el estado, se le opuso la poesía como forma de resistencia. Por esto resulta importante el Diálogo de la flor y el canto en la literatura contemporánea. Es una especie de llamamiento a la acción.

México, Latinoamérica, el mundo hispánico, está dominado por sus contradicciones, por la asimetría social, por la pobreza, por una violencia estructural (llámense políticas neoliberales) que invariablemente alcanza las calles y las tiñe de sangre, las llena de inseguridad, angustia y poca fe en el futuro. La poesía, como única forma de trascendencia, según estos tlamatinime, nos muestra que es posible una sociedad con otros valores. Convivir es un verbo que va más allá de la coyuntura. (Calderón: 2015) ${ }^{41}$.

Lo que nos enseña por tanto el Diálogo de la flor y el canto es que es necesario contraponer a los valores históricos de la coyuntura (poder, riqueza, fama, placeres) la trascendencia, la kenosis, el diálogo humano, la preocupación por el otro.

Podemos pensar en este punto en Heidegger y en uno de los existenciarios de El ser y el tiempo (1988), el ser-para-la muerte, o de cómo el hombre sólo será libre cuando sea consciente de su finitud, del fin de

ma - boca que habla y oreja que oye- será la revelación de aquello que la exclamación señala sin nombrar" (Paz, 1972: 46-47). En su opinión, las labores del acto poético son las siguientes: "La creación poética se inicia como violencia sobre el lenguaje. El primer acto de esta operación consiste en el desarraigo de las palabras. El poeta las arranca de sus conexiones y menesteres habituales: separadas del mundo informe del habla, los vocablos se vuelven únicos como si acabasen de nacer. El segundo acto es el regreso de la palabra: el poema se convierte en objeto de participación" (Ídem: 38).

39- En la entrevista ya citada.

40- Para hablar de este diálogo tenemos que remontarnos a 1487 cuando los aztecas, la tribu nahua más poderosa del valle de México, inauguraron el Templo Mayor con 80,000 sacrificios humanos. Todos los cautivos, los sacrificados, provenían de una comunidad en las faldas del volcán Popocatépetl, Huexotzinco. Tres años más tarde, Tecayehuatzin, Señor de Huexotzingo, convocó a los tlamatinime, a los sabios del mundo nahuatl, a dar respuesta a una sola pregunta: ¿qué vale la pena sobre la faz de la tierra? Todos coincidieron en menospreciar el poder, la riqueza, los placeres y la fama. Concluyeron que lo más significativo era la flor y el canto, es decir, la poesía.

41- En la entrevista ya citada. 
sus posibilidades (1988: 255). Dice Heidegger que "la muerte es la posibilidad de la radical imposibilidad de existir. La muerte se revela así como la posibilidad más propia, irrespectiva e insuperable. Como tal, ella es una inminencia sobresaliente" (1988: 270-271).

Pero la preocupación por el otro está fundamentalmente en Emmanuel Levinas (2002), quien va más allá del ontologismo trágico de Heidegger, y desarrolló el concepto de ser-para-después-de-mi-muerte, con el que apuesta por que lo primero que debe ser pensado no es la muerte propia, sino la muerte del otro. La angustia por la muerte se transforma en el miedo de matar al otro. "La voluntad está bajo el juicio de Dios desde el momento en que el miedo a la muerte se invierte en temor de cometer un asesinato" (Levinas, 2002: 258). Es decir, trascender lo propio, y preocuparse del otro.

\section{La historia de la Conquista y la identidad mexicana}

La identidad mexicana, entendida como arquetipo de la mexicanidad, es uno de los temas principales de la poesía de Alí Calderón ${ }^{42}$ y, en general de la poesía mexicana contemporánea. Ya en Sor Juana Inés de la Cruz se advierte esa búsqueda, como por ejemplo en El divino Narciso, el más conocido y original de sus autos sacramentales. En él, y pese a no ser muy popular en la literatura de su tiempo, Sor Juana aborda el tema de la conquista del Nuevo Mundo y las tradiciones de los pueblo indígenas.

Es de la mezcla, de lo mestizo, de lo que nace lo mexicano. Pero la mezcla racial, tan habitual entre españoles e indígenas una vez comenzada la conquista, era algo negativo en la América del siglo XVI, cuando empezaron los prejuicios que aún hoy perduran. Qué es ser mestizo es uno de los grandes temas de la América Española, y de él se han ocupado con gran lucidez Octavio Paz, Carlos Fuentes y Alejo Carpentier, por mencionar sólo a algunos.

Para Paz, este nuevo tiempo partió de origen de una dualidad entre lo azteca, lo aborigen, y lo español, lo que ha llevado al mexicano actual a situarse tras muchas máscaras, ya sean la fiesta, e incluso la violencia, y esconder sus dudas sobre su propia identidad. Estas máscaras tienen, según Paz, un origen histórico-mítico-psicoanalítico que se relaciona con la concepción del mexicano, y, como objetivo, la deformación de la realidad.

Ante este panorama, la apuesta de Alí Calderón es reivindicar el pasado indígena de México, sin olvidar el papel preponderante de la Conquista. Recuerda que en México se hablan más de quinientas lenguas, lo que puede considerarse como quinientas visiones del mundo distintas:

Si cada lengua es una visión del mundo, las más de quinientas lenguas del territorio mexicano son maneras diferentes de entender y relacionarse con la realidad. La manera en que el español que hablamos en México ha enriquecido a la lengua también da cuenta de una manera particular de estar vivos. Creo que esto se observa con nitidez desde los primeros contactos españoles en México (Calderón: 2015) ${ }^{43}$.

42- No sólo encontramos ese tema en su último libro, Las correspondencias, sino que también tenemos ejemplos en libros anteriores, como Imago Prima (2005).

43- Declaraciones de la entrevista realizada por la autora a Calderón el 13 de octubre de 2015. 
Ya a Hernán Cortés, cuando le describe en su segunda carta de relación a Carlos $\mathrm{V}$ el mercado, el tianguis de Tenochtitlán, no le alcanzan las palabras para nombrar lo que ve después de una hiperbólica enumeración (Cortés, en Gayangos y Arce, 2008: 104).

Este intento de abarcar con la palabra todo lo que ve es la muestra de que la literatura ayuda a reformular la realidad, a ofrecer nuevas interpretaciones de la realidad, es decir, a explicar quiénes somos en lo individual y en lo colectivo, a hallar la identidad propia.

A eso, el poeta Alí Calderón no podía estar ajeno, y para hablar de la identidad mexicana vuelve a acudir a la historia de su país, a su pasado indígena, y reflexiona sobre qué es ser mexicano, y, por tanto, sobre la raza, el gran tema político del siglo XXI:

Todas las disputas del siglo XXI no tienen que ver con la clase social, como pensaba Marx. El mayor antagonismo es el de la raza. Esto se nota con mucha fuerza en los países del tercer mundo (Calderón: 2015).

Calderón considera que lo mexicano es una tercera raza, el mestizo, que puede llegar a idealizar lo indígena pero a la vez, como sostiene Paz, siente desprecio por lo indígena. La actitud es, por tanto, ambigua y paradójica:

Evidentemente lo blanco, lo español, es aspiracional, pero sin embargo no se puede ir contra las evidencias. Por eso el sistema de castas está implantado en el imaginario del mexicano. Hay un dicho popular, un refrán, que puede ilustrar este modo de ser del mexicano, esta idiosincrasia: Como te ven te tratan. Significa que en la medida que alguien esté más cercano a lo español, al criollismo, le irá mejor en la vida, pero eso tiene que ver ante todo con la división racial del trabajo que se instituyó en el siglo XVI, y que sigue vigente en nuestros días. El criollo, el blanco, tiene los puestos dirigenciales, hasta la fecha, el barrendero, el que limpia, está más cercano a lo indígena, hasta la fecha (Calderón: 2015).

En uno de los poemas de su primer libro, Imago Prima (2005), Calderón usa de nuevo la historia de la conquista de América para abordar el tema de la raza. El título de este nuevo texto que analizaremos a continuación es el de Que trata de naufragios y rescates, que versa sobre el primer contacto que tuvo una expedición española con México. En él, Calderón usa, como ya haría después en el poema Democracia Mexicana, en su libro Las correspondencias, el lenguaje de los conquistadores, imitando las crónicas de Cortés y Bernal Díaz del Castillo.

\footnotetext{
En trece días del mes de febrero año de mil quinientos diez y nueve años Hernando de Cortés vino a la isla de Cozumel. (Calderón, Imago Prima, 2005: 98)
} 
La historia la cuenta Bernal Díaz del Castillo en Historia Verdadera de la conquista de la Nueva Espa$\tilde{n} a$ y relata el momento en el que los españoles llegan a una isla llamada Cozumel, frente a Cancún. Era 1519 y el navío de Hernán Cortés se dirigía a lo que después sería México. Cortés supo de dos españoles que estaban en poder de los indios en la punta de Cotoche y los quiso rescatar de la esclavitud a la que estaban sometidos.

"E díjoles Cortés que luego les fuesen a llamar con carta, que en su lengua llaman amales, e dio a los caciques y a los indios que fueron con las cartas, camisas, y los halagó, y les dijo que cuando volviesen les darían más cuentas; y el cacique dijo a Cortés que enviase rescate para los amos con quien estaban, que los tenían por esclavos, porque los dejasen venir" (Díaz del Castillo, 2011: 98).

Los dos españoles a los que Cortés envió una carta ofreciéndoles un rescate y que se libraran de la esclavitud eran el sacerdote Jerónimo Aguilar y el soldado Gonzalo Guerrero. Los dos formaban parte de una expedición que tenía como destino Santo Domingo pero que naufragó. Son precisamente los dos nombres que aparecen en el poema de Calderón:

\author{
Terra adentro \\ Jerónimo de Aguilar, cativo y astroso, \\ sintió gran follía por aquel acaecimiento. \\ Aquellas nuevas eran brisa dus \\ e tibia para la su alma: \\ - ¡Oh luminaria de las tres caras! ${ }^{44}$ \\ Heme aquí arrepiso \\ rodilla en suelo \\ plegando por dexar esta nefaria ${ }^{45}$ nación. \\ E se fue Jerónimo de Aguilar donde Gonzalo Guerrero \\ para le referir lo acapitado \\ (Calderón, Imago Prima, 2005: 98)
}

Aguilar consiguió que el que era su amo le librase de la esclavitud y, después de eso, quiso que también hiciera lo propio su compañero Gonzalo Guerrero, quien sin embargo se había adaptado completamente a la vida maya, era un cacique, y ya había formado una familia que le impedía abandonar la región. Calderón cuenta cómo Aguilar le pidió a su compañero que se uniera a la expedición que se había comprometido a devolverlos a España:

44- El autor se refiere aquí a la Santísima Trinidad, teniendo en cuenta que Jerónimo de Aguilar era sacerdote.

45- Aguilar quiere marcharse de esta nefanda nación, donde estaba esclavo por los mayas, que por entonces practicaban la sodomía. 
E se fue Jerónimo de Aguilar donde Gonzalo Guerrero

para le referir lo acapitado:

- Ave estas cuentas verdes de Castilla, mi buen amigo don Gonzalo,

que nos requiere en el su real

el adelantado de Su Majestad don Carlos.

(Calderón, Imago Prima, 2005: 98)

Sin embargo, Gonzalo Guerrero, rechaza abandonar la tierra en la que ya había construido una familia:

Gonzalo Guerrero, que era tenido como cacique

y capitán de guerra

entre los suyos,

hubo gran lazería en el su coraçón

e respondió:

- Hermano Aguilar, yo soy casado e tengo tres hijos.

Idos con Dios, que yo tengo labrada la cara e

horadadas las orejas.

- Dios Nuestro Señor, que es el socorro verdadero, os dará el perdón.

- Acá nos dé Dios su gracia, hermano Aguilar, no os puedo servir de compaña. Ya veis estos mis hijitos cuan bonicos son...

El mismo episodio lo cuenta Bernal Díaz del Castillo, al que Calderón imita en el lenguaje en este caso:

"Caminó el Aguilar adonde estaba su compañero, que se decía Gonzalo Guerrero, que le respondió: "Hermano Aguilar, yo soy casado, tengo tres hijos, y tiénenme por cacique y capitán cuando hay guerras; idos vos con Dios; que yo tengo labrada la cara e horadadas las orejas; ¿qué dirán de mí desque me vean esos españoles ir desta manera? E ya veis estos mis tres hijitos cuán bonicos son” (Díaz del Castillo, 2011: 99-100).

En el poema, el rechazo de Gonzalo Guerrero indigna entonces a Jerónimo Aguilar. El religioso no entiende que su compañero quiera quedarse, y lo acusa de "necio e desentido", e incluso acaba maldiciéndolo:

E Aguilar lo acusaba de necio e desentido por se quedar:

- ¡Maldito seas de Dios e de todos los sus santos, Gonzalo, sesenta mil satanases te lleven!

(Calderón, Imago Prima, 2005: 100)

Ese momento que relatan las crónicas de la conquista es el que le sirve a Calderón para contar la historia de los que fueron los primeros mestizos de México, de los iniciadores de una nueva raza, ya con una 
genética nueva. Antes de que Hernán Cortés llegara al Yucatán, ya hubo un español que creó una nueva estirpe, una nueva sangre:

- Hermano Aguilar, yo soy casado e tengo tres hijos.

Idos con Dios, que yo tengo labrada la cara e

horadadas las orejas.

(Calderón, Imago Prima, 2005: 99)

Gonzalo Guerrero, que decidió quedarse con los mayas, fue precisamente el que instruyó a los indígenas en las técnicas militares españolas. Así, cuando Francisco de Montejo intentó conquistar Yucatán, en 1527, encontró serias dificultades precisamente por el entrenamiento que los mayas habían recibido de Guerrero. Las enseñanzas de Guerrero ya las descubrió Cortés en 1519, cuando supo que aquello había dificultado mucho la misión de Hernández de Córdoba en 1517, durante el descubrimiento de la península del Yucatán (Díaz del Castillo, 2011: 107).

La importancia de este poema en la obra de Calderón radica en que trata sobre la propia identidad mexicana, de qué es lo mexicano, e incluso puede servir para reflexionar acerca de la actitud de España de los últimos 500 años respecto a sí misma:

"Por un lado España es europea, y voltea los ojos hacia Europa, pero también debe voltear los ojos hacia América. Yo creo que cada vez que ha volteado los ojos hacia Europa ha significado una derrota. Cuando España prefiere a Carlos V en lugar de a su hermano, ahí está la primera gran derrota del mundo hispánico. La segunda es con los borbones, con Felipe V. Cuando mejor le va es cuando se centra en sí misma, como por ejemplo con los Reyes Católicos" (Calderón: 2015).

En este caso, Calderón vuelve a emular el lenguaje de los conquistadores a modo de collage literario. "Tengo un especial amor por el collage. En muchos momentos emulo, imito, utilizo la figura personae, una suerte de monólogo dramático, para resignificar alguna situación” (Calderón: 2015). Se trata de una técnica habitual en la poesía conceptual norteamericana: sacar un texto de su contexto y situarlo en otro para, de ese modo, lograr su resignificación. Apropiarse de otro texto para darle nueva y distinta vida, en este caso las crónicas sobre el descubrimiento del Nuevo Mundo:

A mí las Crónicas de Indias me parecen textos fundacionales del espíritu mexicano, latinoamericano, hispánico en general. Son nuestra épica. Utilizar esas palabras no sólo como un ejercicio gozoso de lenguaje sino también como una posibilidad para potenciar los significados de los poemas (Calderón: 2015).

La presencia de la conquista de América, como una suerte de mirada al pasado para reafirmar el presente, está también en otros poemas de Calderón incluso de carácter amoroso. En Las correspondencias encontramos el poema Gonzalo Pizarro (Trujillo, 1510), Fornezino y profiado, percaça lo que pudo ser y cogita en andando ónix con pórfido tras barata. El poeta escribe sobre Gonzalo Pizarro, pero en realidad 
se refiere a un granadino que se llamaba Gonzalo Jiménez de Quesada, que es el conquistador de Colombia, el fundador de Bogotá.

Tanto Gonzalo Pizarro, que era primo de Francisco Pizarro, que era el conquistador de Perú, como Jiménez de Quesada, estaban obsesionados con encontrar El Dorado, el lugar donde todo brilla, donde todo es oro.

La base histórica del mito tiene como origen probable el ritual que se llevaba a cabo en la laguna de Guatavita, en Colombia, para investir a los nuevos caciques tras la muerte del último. Una masa de tierra mezclada con oro en polvo servía para ungir al sucesor, quien, desde el centro de la laguna, debía arrojar como ofrenda al agua piezas de oro y esmeralda. La creencia de que esa laguna podría tener en sus fondos los más preciados tesoros llevó a muchos de los conquistadores a intentar vaciarla de agua.

Calderón utiliza ese mito de El Dorado como un símbolo para un poema de carácter amoroso, donde juega en tres niveles, y en tres tiempos gramaticales también. Primero el poeta está hablando del tiempo histórico, en presente, un tiempo histórico del siglo XVI en presente, después de la belleza de una muchacha en un lenguaje coloquial pero en un tiempo futuro, y finalmente de la cetrería como metáfora de la conquista amorosa en subjuntivo, lo que se puede ya observar desde los primeros versos:

\author{
Ya Gonzalo Jiménez de Quezada trebejos pan cazabe $e^{46}$ \\ avanza hacia la jungla \\ Tú estarás caminando por la sesenta y cinco \\ envuelta por el aire frío que baja desde Montserrate \\ Fuera todo cuestión de cetrería \\ (Calderón, Las correspondencias, 2015: 50)
}

Calderón elige a un Jiménez de Quesada que no es tan conocido como Cortés o como Díaz del Castillo. Él tenía veintisiete años cuando fue nombrado, en 1536, jefe de una expedición hacia el interior de Colombia con el objetivo de hallar la fuente del río Magdalena y así encontrar también una ruta a Perú y el Pacífico.

En su libro Los conquistadores: una breve introducción (2012), Mathew Restall y Felipe Fernández Armesto cuentan cómo este conquistador vivió unos dos años entre los muisca, un pueblo indígena que ha habitado el altiplano al sur del departamento de Santander, en la actual Colombia, desde el siglo VI a. C.

Bajo la sombra de la estatua

de Bolivar entiendo

que siempre está allá más allá

por poner un ejemplo: tus pestañas

que Tántalo ${ }^{47}$ que los joyeles

46- En su Epitome de la conquista del Nuevo Reino de Granada, González de Quesada hace referencia a diferentes voces indoamericanas tomadas de las lenguas precolombinas, por ejemplo el maíz o la yuca. Cuando Calderón se refiere al pan cazabe a las llamadas tortas de cazabe, que los indígenas hacían con la raíz de la yuca (Galeote, 2005: 173-189). 
del oro muisca más perfectos

el aúreo silencio de tus selfies

$y$ fotos de perfil

yacen plomo en el fango

las Guatavitas diarias imposibles

(Calderón, Las correspondencias, 2015: 52)

Calderón mezcla en esta parte del poema el siglo XVI de Jiménez de Quesada y el presente, aludiendo al oro muisca y a las Guatavitas, e introduciendo términos de modernidad como "selfies" o "fotos de perfil". La idea del poema, es que así como El Dorado era una ilusión imposible de alcanzar, la muchacha también es imposible de conseguir.

\section{En El Dorado aguardo}

con la amargura del que vuelve a casa

Esta espera de sangre y bilis y veneno

se parece a la ausencia que suelo ser que fui

si de pronto tus labios

se aproximan de nuevo y me repiten:

Todo no vale nada

Si lo demás acaso vale menos

(Calderón, Las correspondencias, 2015: 52)

La caza del halcón y la presa, fracasa, es infructuosa (Pierdan su presa halcones altaneros). Así como no se logró llegar al Dorado, no se logra la muchacha, y simplemente estas figuras históricas, estos pequeños símbolos históricos, le sirven al poeta para ilustrar una historia amorosa.

\section{Conclusión}

En definitiva, para Calderón (2015), la poesía tiene una tradición, es decir, una suma de experiencias técnicas y de motivos y temas a lo largo de la historia. Esa tradición es la plataforma a partir de la cual se debe construir la poesía:

El objetivo de un poeta, al menos, sería volverse contemporáneo de su propio tiempo, del tiempo en que vive. Si la poesía, el arte en general, tiene un carácter mimético ¿cómo dar cuenta de la complejidad, la incertidumbre, la hiperinformación, las distintas dimensiones de la identidad, la liquidez (para utilizar el concepto de Sygmunt

\footnotetext{
a su hijo Pélope en un banquete a los dioses del Olimpo. Lo descuartizó, coció sus miembros y los sirvió a los comensales. Tántalo fue por ello eternamente torturado y condenado a permanecer en un lago bajo un árbol repleto de frutas que se retiraban cada vez que quería tomar alguna de ellas (Monge, 1997: 116-123).
} 
Bauman) que caracterizan a nuestras vidas? ¿Con qué procedimientos técnicos expresar la velocidad en que vivimos y nos movemos? ¿Cómo referir la manera en que experimentamos el amor, el gozo, la esperanza? $\mathrm{O}$ ¿es que Hesíodo experimentaba los ritmos del mundo del mismo modo en que nosotros? ¿Los poetas del dulce estilo nuevo aman como nosotros amamos? Ciertamente no.

En nuestra opinión, comparte Calderón la definición de Charles Simic sobre escribir poesía: "atrapar un gato negro en un cuarto oscuro" (2003), una idea a la que, si sumamos el ingrediente del entorno histórico-social nos da como resultado el concepto del inconsciente colectivo que desarrolló Carl Jung.

En la última poesía de Calderón encontramos paralelismos interesantes entre el México prehispánico y el actual. El derramamiento de sangre de los aztecas ante la piedra de sacrificio continúa hoy en las ciudades y los pueblos del país. La constante, lo que hemos llamado el arquetipo de la mexicanidad, la conducta constante, el inconsciente colectivo, no sólo gira en torno a lo mestizo, sino también en torno a la sangre, al sacrificio. México repite su historia de la misma forma que el águila devoraba cada día el hígado del Prometeo inmortal; el país está, como constatamos en la poesía de Alí Calderón, continuamente en la piedra de sacrificio.

\section{Referencias}

Arola, Raimon. 2008. Alquimia y religión. Los símbolos herméticos del siglo XVII. Madrid: Ediciones Siruela.

Balderas Vega, Gonzalo. 2008. Cristianismo, sociedad y cultura en la Edad Media. Una visión contextual. México DF: Plaza y Valdés.

Baudelaire, Charles. 2014. Las flores del mal. Barcelona: Planeta.

Calderón, Alí. 2005. Imago Prima. México: Universidad Autónoma de Zacatecas.

_ 2015. Las correspondencias. Madrid: Visor Libros.

Carpentier, Alejo. 1981. La novela latinoamericana en vísperas de un nuevo siglo y otros ensayos. Madrid: Siglo XXI.

_ 1984. Razón de ser. La Habana: Editorial Letras Cubanas.

CNN en español. 2015. Autoridades encuentran cuerpo colgado de puente en la Ciudad de México. 15 de octubre.

Comisión Nacional de los Derechos Humanos de México. 2015. El tema migratorio, de urgente abordaje. http://www.cndh.org.mx/sites/all/doc/Comunicados/2015/Com_2015_380.pdf (18 de diciembre de 2015).

Consejo Nacional de la Política de Desarrollo Social de México. 2014. Medición de la pobreza. http:// www.coneval.gob.mx/Medicion/MP/Paginas/AE_pobreza_2014.aspx (23 de julio de 2015).

Cortázar, Julio. 2003. Obras completas. Cuentos. Barcelona: Galaxia Gutenberg-Círculo de Lectores.

Díaz del Castillo, Bernal. 2011. Historia verdadera de la conquista de la Nueva España, estudio y notas de Guillermo Serés. Madrid: Real Academia Española - Barcelona: Espasa-Círculo de Lectores.

El Mundo. 2015. México: la guerra del Estado contra el 'narcoestado', de Javier Brandoli. 
http://www.elmundo.es/internacional/2015/07/14/55a4075822601de54c8b45a8.html (14 de julio de 2015).

El informador. 2013. Hallan bebé muerto en un basurero. http://www.informador.com.mx/jalisco/2013/453887/6/hallan-bebe-muerto-en-un-basurero.htm (27 de abril de 2013).

El País. 1983. México tuvo una inflación del ciento por ciento en 1982.http://elpais.com/diario/1983/01/07/ economia/410742007_850215.html (7 de enero de 1983).

El País. 1985. La movilización popular pone en tela de juicio la eficacia del Gobierno. http://elpais.com/ diario/1985/09/23/internacional/496274413_850215.html (23 de septiembre de 1985).

El País. 2015. Crimen sin Castigo, de Ernesto Krauze. http://elpais.com/elpais/2015/11/06/opinion/1446830205_420907.html (9 de noviembre de 2015).

El Universal. 2008. Afirma Krauze que se debe evitar que México sea narco-Estado. Sin firma. http:// archivo.eluniversal.com.mx/notas/547793.html (17 de octubre de 2008).

Fuentes, Carlos. 1998. El espejo enterrado. Madrid: Taurus.

Galeote, Manuel. 2005. Indoamericanismos en el epítome de Jiménez de Quesada. Pensamiento y Cultura, 8: 173-189.

Gayangos y Arce, Pascual de. 2008. Cartas y relaciones de Hernán Cortés al emperador Carlos V. Sevilla: Extramuros Edición.

Goldsmith, Kenneth. 2011. Uncreative writing. Nueva York: Columbia University Press.

González Torres, Yolotl. 1985. El sacrificio humano entre los mexicas. México: Fondo de Cultura Económica.

Grillo, Ioan. 2012. El Narco: en el corazón de la insurgencia criminal mexicana. Barcelona: Tendencias Editores.

Heidegger, Martin.1988. El ser y el tiempo. México: Fondo de Cultura Económica.

Hoppe-Navarro, Márcia. 2011. El mito de la Malinche en la obra reciente de escritoras hispanoamericanas Mitologías hoy: Revista de pensamiento, crítica y estudios literarios latinoamericanos, 4: 5-14.

Jung, Carl Gustav. 1992. Arquetipos e inconsciente colectivo. Barcelona: Paidós.

_(1995). El hombre y sus símbolos. Buenos Aires: Paidós.

_(1999) Obra completa. Volumen 8. La dinámica de lo inconsciente. Madrid: Editorial Trotta.

Kayser, Wolfgang. 1954. Interpretación y análisis de la obra literaria. Madrid: Editorial Gredos.

León Portilla, Miguel. 1961. Los antiguos mexicanos. México: Fondo de Cultura Económica.

Levinas, Emmanuel. 2002. Totalidad e infinito. Ensayo sobre la exterioridad. Salamanca: Ediciones Sígueme.

Lira, Andrés y Luis Muro. 1976. Historia general de México. México: El Colegio de México.

Marx, Karl. 2015. El 18 Brumario de Luis Bonaparte. Madrid: Alianza Editorial.

Monge, José Antonio. 1997. El suplicio de Tántalo. Historia 16, 260: 116-123.

Morante, José Luis. Re-generación. Granada: Valparaíso Ediciones.

Motolinía. 1971. Memoriales. Libro de las cosas de la Nueva España y de los naturales de ella. México: UNAM, Instituto de Investigaciones Históricas.

NBC News. 2010. Mexican gang drug barricades Monterrey roads. http://www.nbcnews.com/ id/38707292/39779522\#.VoGs7PnhC1s (14 de agosto de 2010).

Paz, Octavio. 1972. El arco y la lira. México DF: Fondo de Cultura Económica. 
_1981. El Laberinto de la soledad. México DF: Fondo de Cultura Económica.

Perloff, Marjorie. 2010. Unoriginal Genius: Poetry by Other Means in the New Century. Chicago: University of Chicago Press.

Pound, Ezra. 1973. El arte de la poesía. México: Editorial Joaquín Mortiz. _(1999). Cantares completos. Madrid: Cátedra.

Poniatowska, Elena y Antonio García de León. 1994. EZLN. Documentos y comunicados. $1^{\circ}$ de enero/8 de agosto de 1994. México D.F.: Ediciones Era.

Restall, Mathew y Felipe Fernández-Armesto. 2012. Los conquistadores: una breve introducción. Madrid: Alianza Editorial.

Riffaterre, Michael. 2000. La ilusión de écfrasis. En Literatura y pintura, de Antonio Monegal. Madrid. Arco / Libros, 161-183.

Salazar, Alonso. 2012. La parábola de Pablo. Bogotá: Planeta.

Sánchez García, Remedios. 2015. El canon abierto. (Última poesía en español). Madrid: Visor.

Saviano, Roberto, 2014. CeroCeroCero. Barcelona: Anagrama.

Seguridad, Justicia y Paz. 2014. Ranking de las ciudades más violentas del mundo. http://www.seguridadjusticiaypaz.org.mx/biblioteca/download/6-prensa/177-por-tercer-ano-consecutivo-san-pedro-sulaes-la-ciudad-mas-violenta-del-mundo (15 de enero de 2014).

Simic, Charles. 2003. Una mosca en la sopa. Barcelona: Vaso Roto Ediciones.

Sor Juana Inés de la Cruz. 1994. Obra selecta. Caracas: Biblioteca Ayacucho.

Soto Gamboa, Ángel. 2004. Historia del presente: Estado de la cuestión y conceptualización. Historia Actual Online, 3: 101-116.

VV.AA. 2011. Poesía ante la incertidumbre. Antología (Nuevos poetas en español). Madrid: Visor. 